\title{
Ultrathin Nanocrystalline Magnetic Wires
}

\author{
Horia Chiriac, Nicoleta Lupu, George Stoian, Gabriel Ababei, Sorin Corodeanu \\ and Tibor-Adrian Óvári *
}

National Institute of Research and Development for Technical Physics, 47 Mangeron Blvd., Iași 700050, Romania; hchiriac@phys-iasi.ro (H.C.); nicole@phys-iasi.ro (N.L.); gstoian@phys-iasi.ro (G.S.); gababei@phys-iasi.ro (G.A.); scorodeanu@phys-iasi.ro (S.C.)

* Correspondence: taovari@phys-iasi.ro; Tel.: +40-232-430680

Academic Editors: Helmut Cölfen and Arkady Zhukov

Received: 2 December 2016; Accepted: 4 February 2017; Published: 10 February 2017

\begin{abstract}
The magnetic characteristics of FINEMET type glass-coated nanowires and submicron wires are investigated by taking into account the structural evolution induced by specific annealing all the way from a fully amorphous state to a nanocrystalline structure. The differences between the magnetic properties of these ultrathin wires and those of the thicker glass-coated microwires and "conventional" wires with similar structures have been emphasized and explained phenomenologically. The domain wall propagation in these novel nanowires and submicron wires, featuring a combination between an amorphous and a crystalline structure, has also been studied, given the recent interest in the preparation and investigation of new materials suitable for the development of domain wall logic applications.
\end{abstract}

Keywords: nanocrystalline magnetic nanowires; nanocrystalline submicron wires; rapidly solidified magnetic materials

\section{Introduction}

Long cylindrical ferromagnetic wires with excellent soft magnetic properties [1,2] have been of interest for numerous applications, mainly in sensing devices such as electrical current and magnetic field sensors aimed for medical and automotive uses [3-5]. To obtain a low coercivity, $H_{C}$, accompanied by a high relative magnetic permeability, $\mu_{r}$, such materials have been produced mainly in amorphous state, in order to avoid any magnetocrystalline anisotropy. The employed preparation methods include various rapid solidification techniques, which led to magnetically soft amorphous wires with different dimensions (diameter, length).

Two main types of soft magnetic amorphous wires have been prepared and investigated:

(i) in-rotating-water quenched ones, usually referred to as "conventional" amorphous wires [6-9], and

(ii) glass-coated ones, referred to as glass-coated or glass-covered amorphous microwires [10-12].

The "conventional" amorphous wires, prepared by the so-called in-rotating-water spinning method [13], usually exhibit diameters ranging between 80 and $150 \mu \mathrm{m}$. The glass-coated amorphous microwires, prepared by means of glass-coated melt spinning [14], display much smaller diameters of the magnetic wire, ranging from 1 to $50 \mu \mathrm{m}$. However, these are composite materials, since the actual magnetic wires are directly obtained in an insulating glass coating, which has a thickness of 1 to $50 \mu \mathrm{m}$ itself. Both the 'conventional' and the glass-coated samples are prepared through continuous processes, which result in very long wires (tens to hundreds of meters in the case of "conventional" wires, and even thousands of meters in the case of glass-coated microwires). 
There are three main alloy groups that have been commonly used to produce the amorphous magnetic wires and microwires:

(1) Alloys with large and positive magnetostriction, $\lambda$, such as $\mathrm{Fe}_{77.5} \mathrm{Si}_{7.5} \mathrm{~B}_{15}$ with $\lambda \cong 25 \times 10^{-6}$;

(2) Those with negative magnetostriction, e.g., $\mathrm{Co}_{80} \mathrm{Si}_{10} \mathrm{~B}_{10}$ with $\lambda \cong-4 \times 10^{-6}$; and

(3) Those with nearly zero magnetostriction, for example $\left(\mathrm{Co}_{0.94} \mathrm{Fe}_{0.06}\right)_{72.5} \mathrm{Si}_{12.5} \mathrm{~B}_{15}$ with $\lambda \cong-1 \times 10^{-7}$.

Amorphous wires and microwires from the third group usually exhibit the softest magnetic properties, due to their very small magnetostriction, which, coupled with the large internal stresses induced during preparation, $\sigma$, leads to a quite small magnetoelastic anisotropy $\left(K_{m e} \propto \lambda \cdot \sigma\right)$. Their cylindrical shape, along with the large permeability, has made them suitable for applications based on the giant magneto-impedance effect [15-17], effect that has been also emphasized in other types of magnetic wires, mainly composite ones, e.g., CuBe ones with NiFe plating [18] or $\mathrm{Cu}$ ones with $\mathrm{Co}$ and $\mathrm{Co} / \mathrm{Cu} / \mathrm{Co}$ plating [19]. Composite wires with FeNiCo plating have been also investigated due to their remarkable bistable behavior [20].

A significant breakthrough has been accomplished with the preparation of nanocrystalline wires and microwires from amorphous precursors [21]. This new type of structure, emphasized first in ribbon-shaped magnetic materials [22-24], has been successfully obtained in wire-shaped materials as well, following similar annealing procedures, e.g., $60 \mathrm{~min}$ in vacuum at $550{ }^{\circ} \mathrm{C}$ [25]. It consists of nanosized crystalline grains, with typical dimensions between 10 and $50 \mathrm{~nm}$, embedded in a residual amorphous matrix. This unique structure appears following a well-defined annealing method, which causes the nanosized crystalline grains to nucleate and subsequently grow in the initially fully amorphous precursor material. One typical alloy composition in which such a structure has been emphasized and widely investigated is $\mathrm{Fe}_{73.5} \mathrm{Cu}_{1} \mathrm{Nb}_{3} \mathrm{Si}_{13.5} \mathrm{~B}_{9}$, better known as FINEMET [26]. Magnetic materials with this combined structure-crystalline and amorphous-exhibit outstanding soft magnetic properties, usually comparable or superior to those of nearly zero magnetostrictive amorphous ferromagnetic materials. This is due to the specific interaction between the nanosized grains and the amorphous matrix [27], which leads to an averaged out zero overall magnetostriction [28].

More recently, following the successful preparation of amorphous submicron wires and nanowires by means of rapid solidification [29], new application prospects have opened for the wire shaped magnetic materials: domain-wall-based magnetic logic applications. Although the domain wall propagation characteristics have been extensively investigated in the 'conventional' wires and in the glass-coated microwires [30], their actual use in magnetic logic applications was hindered by their quite large diameters. This barrier has been broken down with the improvements in the glass-coated melt spinning technique that allowed the continuous preparation of amorphous glass-coated nanowires and submicron wires, with diameters of the actual magnetic wires between 100 and $900 \mathrm{~nm}$. Naturally, the method is also suitable for the preparation of $\mathrm{Fe}_{73.5} \mathrm{Cu}_{1} \mathrm{Nb}_{3} \mathrm{Si}_{13.5} \mathrm{~B}_{9}$ amorphous precursors.

Here we report on the magnetic properties of the $\mathrm{Fe}_{73.5} \mathrm{Cu}_{1} \mathrm{Nb}_{3} \mathrm{Si}_{13.5} \mathrm{~B}_{9}$ nanowires and submicron wires, focusing on the origins of their peculiar characteristics and on the relation between structure and properties, as the former evolves from amorphous to nanocrystalline. The domain wall propagation has been also analyzed, given its importance in the newly sought domain wall logic applications.

The difference between the optimum annealing temperatures found in nanocrystalline ultrathin wires (nanowires and submicron wires) on one hand, and in nanocrystalline microwires, on the other, has been analyzed and discussed. The results show that this difference arises mainly from the interplay between the inter-grain distance and the characteristic exchange length.

\section{Materials and Methods}

Ultrathin $\mathrm{Fe}_{73.5} \mathrm{Cu}_{1} \mathrm{Nb}_{3} \mathrm{Si}_{13.5} \mathrm{~B}_{9}$ nanocrystalline cylindrical samples have been prepared starting from amorphous precursors, in order to study more thoroughly the effects of the significant reduction in diameter on their structural and magnetic characteristics. 
The precursor amorphous $\mathrm{Fe}_{73.5} \mathrm{Cu}_{1} \mathrm{Nb}_{3} \mathrm{Si}_{13.5} \mathrm{~B}_{9}$ submicron wires and nanowires, with diameters ranging between 100 and $900 \mathrm{~nm}$ and the glass coating thickness of $5 \mu \mathrm{m}$, have been prepared by means of glass-coated melt spinning [14], with the necessary improvements that allowed a significant reduction in the diameter of the actual magnetic wires [31]. Hence, in this well-known technique, a special attention has been paid to increase the drawing speed and attenuate the associated vibrations at the same time, in order to keep the wire forming process continuous even at such small diameters of the metallic nucleus. The most important parameter is the surface tension of the molten alloy, which must be optimal in order to ensure its continuous flow through the softened glass capillary. Therefore, the alloy should be overheated more than in the case of the glass-coated microwires prepared through the same glass-coated melt spinning method. Additional changes in this rapid solidification technique refer to the cooling of the nanowire, which has been adapted to the novel, much smaller transverse dimensions.

The magnetic alloy of interest has been prepared from high purity powders, which have been compacted and subsequently induction melted, to make the necessary pieces for the melt spinning rapid solidification technique. Afterwards, the as-quenched amorphous wire samples have been subjected to conventional furnace annealing in vacuum, at temperatures $T_{\text {ann }}$ between $250{ }^{\circ} \mathrm{C}$ and $650^{\circ} \mathrm{C}$, for durations $t_{\text {ann }}$ from $5 \mathrm{~min}$ to $60 \mathrm{~min}$.

The annealing set-up that we have employed for our nano- and submicron-sized samples, schematically shown in Figure 1, allows isothermal annealing in vacuum or in a controlled atmosphere, e.g., Ar. It also allows the cooling of the sample down to room temperature in vacuum, outside the furnace area, avoiding in this way any unnecessary extra annealing during the system warm-up or cooling. The temperature regulator ensures automatically a uniform annealing temperature within a range of $\pm 1^{\circ} \mathrm{C}$ of the set temperature.

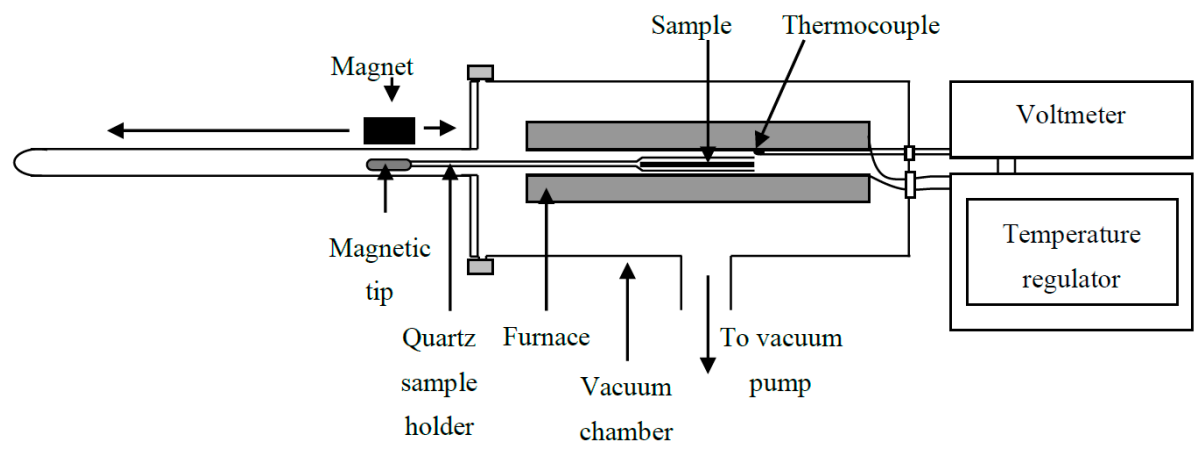

Figure 1. Schematic of the furnace annealing system.

The sample is introduced within the furnace by moving the magnet, only after the annealing temperature has been reached. The magnet is also employed to remove the sample from the furnace after annealing is completed. This system has been designed to allow annealing up to a maximum temperature of $800^{\circ} \mathrm{C}$.

High resolution scanning electron microscopy (HR-SEM, Carl Zeiss Microscopy GmbH, Oberkochen, Germany) has been carried out using a NEON 40 EsB CrossBeam system with In-Lens and backscattered electrons (BSE) detectors. Ultra-high resolution transmission electron microscopy (UHR-TEM), scanning transmission electron microscopy (STEM), and selected area electron diffraction (SAED), have been employed to investigate the microstructure evolution with annealing by using a LIBRA 200MC UHR-TEM (Carl Zeiss Microscopy GmbH, Oberkochen, Germany). The samples for UHR-TEM and STEM investigations have been made using the focused ion beam (FIB) technique for thin TEM lamella preparation [32]. Energy dispersive X-ray spectroscopy (EDS) and electron energy loss spectroscopy (EELS) have been used to check the nominal composition of the nanowires. The results have shown negligible variations with respect to the composition of the initial alloy. 
The hysteresis loops have been measured using an inductive method which employs a digital integration technique, and that has been developed specifically for ultrathin wires, such as the submicron wires and nanowires prepared by glass-coated melt spinning [33]. This method is only suitable for magnetically bistable samples, which always exhibit rectangular hysteresis loops, and is based on a digital integration technique.

Figure 2 shows a schematic of the experimental setup. Its main components are: (i) a magnetizing solenoid; (ii) a system of pick-up coils; (iii) a low-noise preamplifier; (iv) a function generator; and (v) a data acquisition board. The length of the samples measured with this system is about $4 \mathrm{~cm}$, whilst the diameter can take any value between 90 and $1000 \mathrm{~nm}$. The technique, which employs the so-called window method [34], works for any magnetically bistable ultra-thin wire, and the resulting hysteresis loop is a noise-free one, as illustrated in the following section.

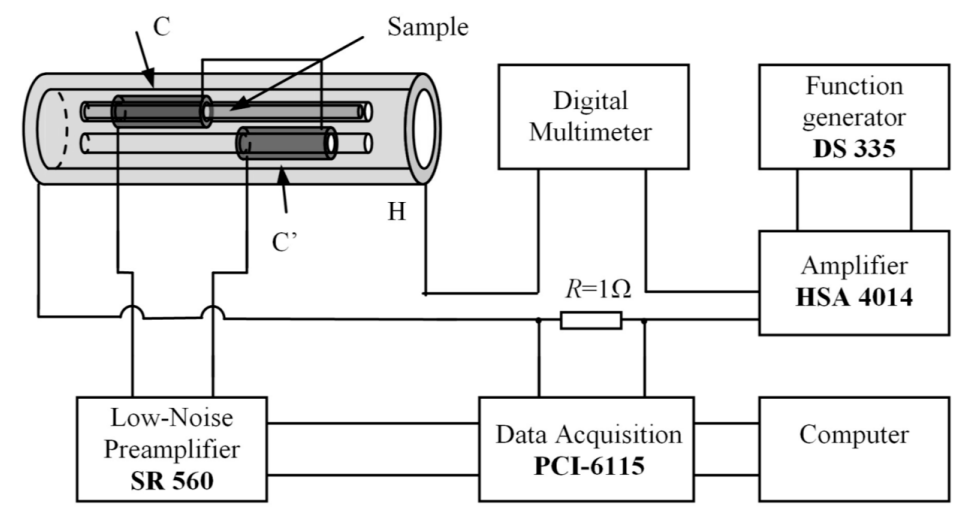

Figure 2. Schematic of the experimental setup for hysteresis loop measurements in amorphous glass-coated nanowires and submicron wires.

The domain wall velocity has been measured using an improved Sixtus-Tonks technique, with four pick-up coils, to allow the detection of walls with any additionally nucleated domains that could alter the precision of the measurements. This method has been refined in order to adapt it for the very small transverse dimensions of the nanowires and submicron wires [35]. Figure 3 shows a schematic of the system developed for the domain wall velocity measurements in the amorphous glass-coated nanowires and submicron wires.

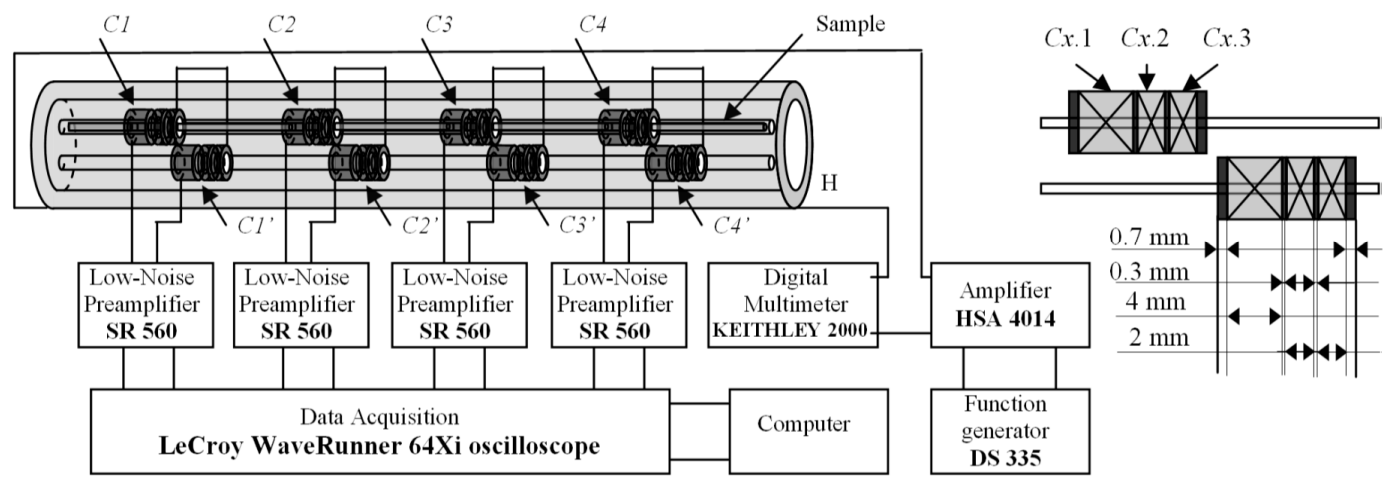

Figure 3. Schematic of the improved system employed for domain wall velocity measurements in amorphous glass-coated nanowires and submicron wires prepared by means of glass-coated melt spinning.

This set-up allows one to pick up the extremely small signals associated with such ultrathin wires. The matter of small signals has been addressed by using two identical systems of four pick-up coils which are connected in series-opposition in order to obtain a compensated system which provides 
only the signal due to the propagating domain walls. In order to easily detect the direction of the propagating domain walls, each of the four pick-up coils has had three windings, with the middle one being wound in the opposite direction with respect to the other two.

\section{Results and Discussion}

Figure 4 shows two scanning electron microscopy (SEM) micrographs:

(i) The first one, shown in Figure $4 \mathrm{a}$, is for a glass-coated $\mathrm{Fe}_{73.5} \mathrm{Cu}_{1} \mathrm{Nb}_{3} \mathrm{Si}_{13.5} \mathrm{~B}_{9}$ nanowire with the diameter of the actual magnetic wire (the so-called metallic nucleus), $\Phi_{m}$, of $185 \mathrm{~nm}$ and the glass coating thickness, $t_{g}$, of about $5 \mu \mathrm{m}$; and

(ii) The second one, illustrated in Figure $4 \mathrm{~b}$, is for a glass-coated microwire having the same composition, but larger transverse dimensions: $\Phi_{m}=3.5 \mu \mathrm{m}$ (metallic nucleus diameter) and $t_{g}=10 \mu \mathrm{m}$ (glass coating thickness).

The second one is given for comparison.

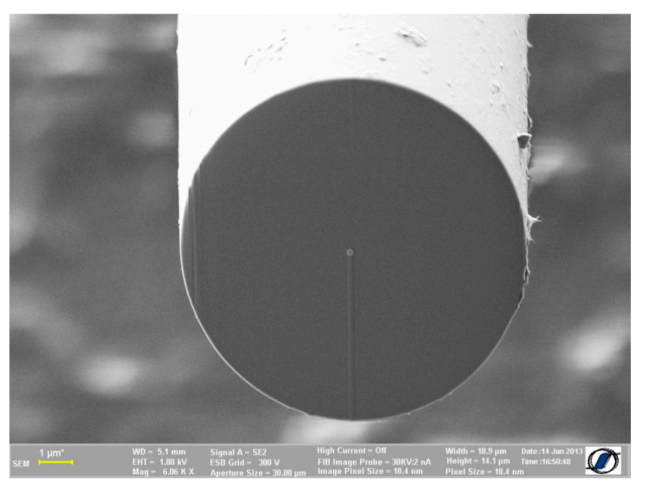

(a)

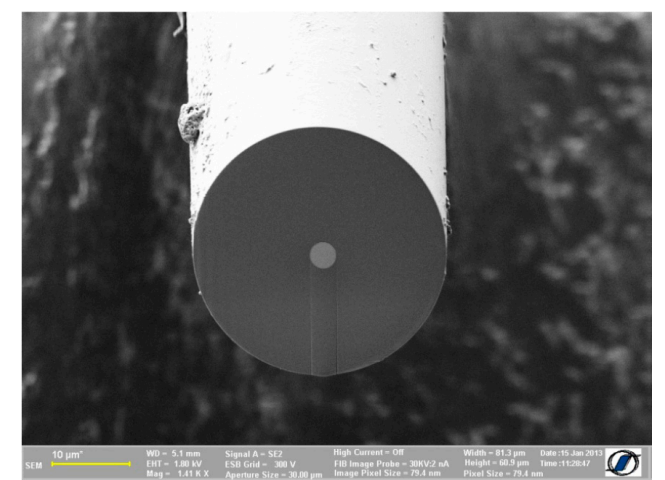

(b)

Figure 4. SEM micrographs of: (a) a glass-coated $\mathrm{Fe}_{73.5} \mathrm{Cu}_{1} \mathrm{Nb}_{3} \mathrm{Si}_{13.5} \mathrm{~B}_{9}$ nanowire with the metallic nucleus diameter of $185 \mathrm{~nm}$ and the glass coating thickness of $5 \mu \mathrm{m}$; and (b) a glass-coated microwire with the same composition, but with the nucleus diameter of $3.5 \mu \mathrm{m}$ and the glass coating thickness of $10 \mu \mathrm{m}$.

The structural changes discussed in the following, along with the corresponding variations in the magnetic characteristics of the samples, are the result of annealing using various parameters: annealing temperature, $T_{a n n}$, and annealing time, $t_{a n n}$. All samples have been annealed in vacuum at temperatures between $250{ }^{\circ} \mathrm{C}$ and $650{ }^{\circ} \mathrm{C}$, for durations up to $60 \mathrm{~min}$.

Figure 5a shows the axial hysteresis loops (axial magnetization vs. axially applied magnetic field) in case of a sample with $\Phi_{m}=185 \mathrm{~nm}$ and $t_{g}=5 \mu \mathrm{m}$ for the annealing temperature $T_{\text {ann }}$ of $550{ }^{\circ} \mathrm{C}$ with the annealing time, $t_{a n n}$, as a parameter. Figure $5 \mathrm{~b}$ shows the hysteresis loops for the same sample, for $T_{a n n}=600^{\circ} \mathrm{C}$, again with $t_{a n n}$ as a parameter.

One observes that the hysteresis loops are rectangular in all cases, which shows that the samples are magnetically bistable in their as-cast state, as well as after various stages of annealing. Magnetic bistability is a clear indicator of a single step axial magnetization reversal process, which occurs when the axial field reaches a certain value, called switching field, $H^{*}$. In both cases illustrated in Figure 5, $H^{*}$ reaches minimum values after annealing for $60 \mathrm{~min}$, showing that the samples become magnetically softer after longer annealing. Nevertheless, the value reached after annealing at $600{ }^{\circ} \mathrm{C}$ for $60 \mathrm{~min}$ is considerably smaller $(\sim 4.6 \mathrm{kA} / \mathrm{m})$ than the value reached following the annealing at $550{ }^{\circ} \mathrm{C}$ for $60 \mathrm{~min}(\sim 7.0 \mathrm{kA} / \mathrm{m})$, indicating that annealing at a slightly more elevated temperature than the typical one employed for ribbons, 'conventional' wires and glass-coated microwires, i.e., $600{ }^{\circ} \mathrm{C}$ instead of $550{ }^{\circ} \mathrm{C}$, is more effective in inducing the process of nanocrystalline phase formation in these ultrathin wires. 


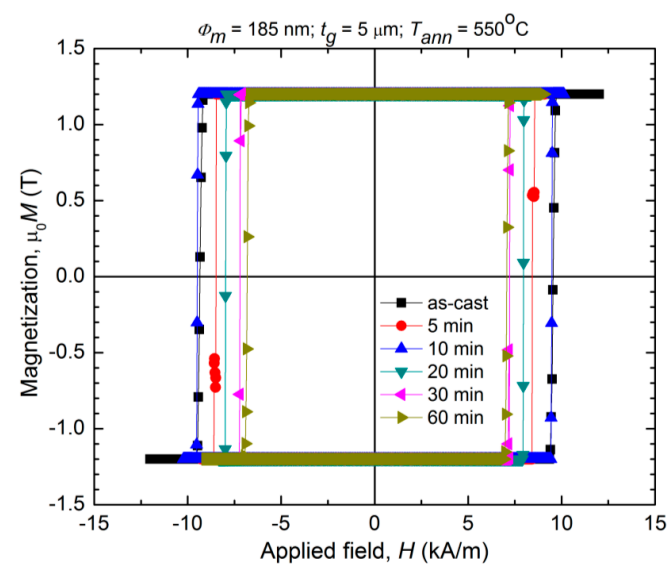

(a)

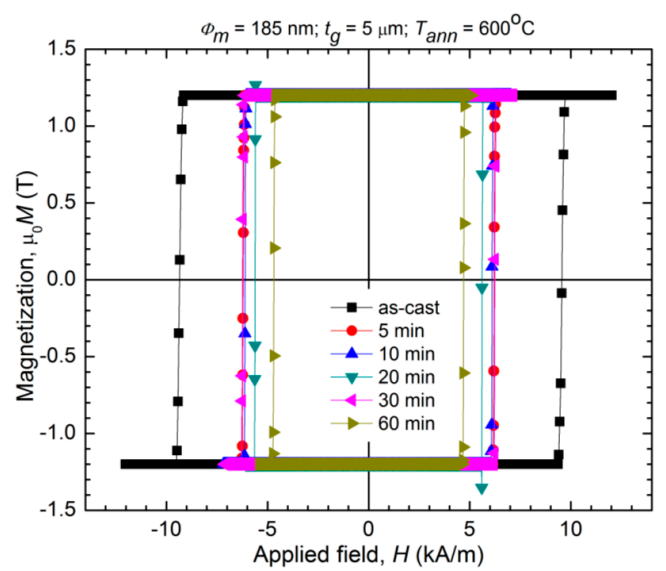

(b)

Figure 5. Axial hysteresis loops of a glass-coated $\mathrm{Fe}_{73.5} \mathrm{Cu}_{1} \mathrm{Nb}_{3} \mathrm{Si}_{13.5} \mathrm{~B}_{9}$ nanowire with the metallic nucleus diameter of $185 \mathrm{~nm}$ and the glass coating thickness of $5 \mu \mathrm{m}$, with the annealing time as a parameter: (a) for an annealing temperature of $550{ }^{\circ} \mathrm{C}$; and (b) for the annealing temperature of $600{ }^{\circ} \mathrm{C}$.

To further substantiate this statement and for comparison, in Figure 6 we have shown the hysteresis loops for the typical glass-coated microwire with the same composition and larger transverse dimensions $\left(\Phi_{m}=3.5 \mu \mathrm{m}, t_{g}=10 \mu \mathrm{m}\right)$, using the same annealing temperatures, i.e., $550{ }^{\circ} \mathrm{C}$-Figure $6 \mathrm{a}$, and $600{ }^{\circ} \mathrm{C}$-Figure $6 \mathrm{~b}$, respectively. The same annealing durations have been employed.

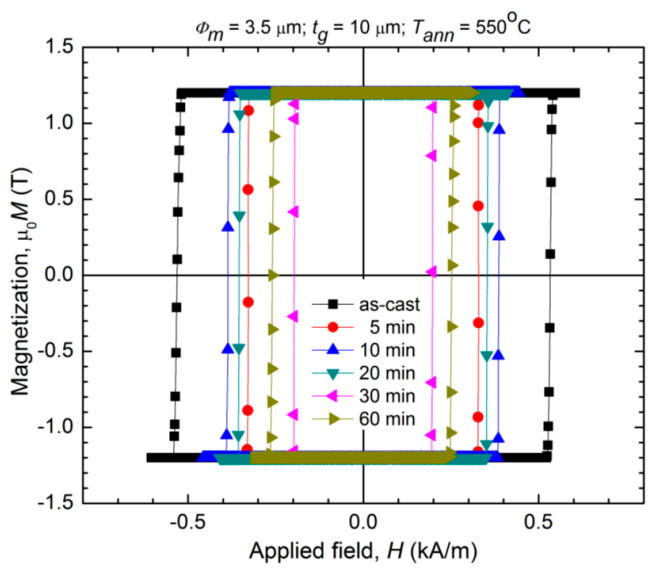

(a)

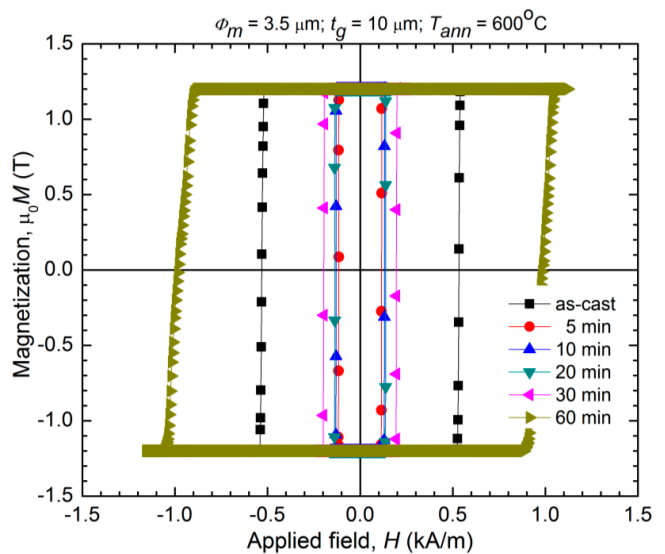

(b)

Figure 6. Axial hysteresis loops of a glass-coated $\mathrm{Fe}_{73.5} \mathrm{Cu}_{1} \mathrm{Nb}_{3} \mathrm{Si}_{13.5} \mathrm{~B}_{9}$ microwire with the metallic nucleus diameter of $3.5 \mu \mathrm{m}$ and the glass coating thickness of $10 \mu \mathrm{m}$, with the annealing time as a parameter: (a) for an annealing temperature of $550{ }^{\circ} \mathrm{C}$; and (b) for the annealing temperature of $600{ }^{\circ} \mathrm{C}$.

One observes that in the case of this microwire sample, the annealing times required to reach the minimum value of the switching field are significantly smaller- $H^{*}$ reaches to slightly below $200 \mathrm{~A} / \mathrm{m}$ after annealing at $550{ }^{\circ} \mathrm{C}$ for $30 \mathrm{~min}$, and to about $120 \mathrm{~A} / \mathrm{m}$ after annealing for just $5 \mathrm{~min}$ at $600{ }^{\circ} \mathrm{C}$. The values of $H^{*}$ are also much smaller (one order of magnitude) than in the case of the ultrathin wire with $185 \mathrm{~nm}$ in diameter. This can be ascribed to at least two factors:

(i) The larger shape anisotropy in the case of the thinner wire, and

(ii) The larger magnetoelastic contribution due to larger mechanical internal stresses induced during preparation. 
In fact, the $4.6 \mathrm{kA} / \mathrm{m}$ value for $H^{*}$ is the smallest one could reach after all the combinations of annealing times and temperatures tested on this type of ultrathin sample. This value should correspond to the formation of the actual nanocrystalline state, with the typically sized $\alpha$-FeSi grains uniformly dispersed throughout the remaining amorphous matrix. Annealing at $650{ }^{\circ} \mathrm{C}$ resulted in a substantial increase of $H^{*}$, up to almost $16 \mathrm{kA} / \mathrm{m}$, most likely due to further crystallization and the associated increase in the grain size, beyond the average values encountered in the nanocrystalline phase.

Figure 7 shows the SEM micrograph of a thin microwire sample annealed at $550{ }^{\circ} \mathrm{C}$ for $60 \mathrm{~min}$.

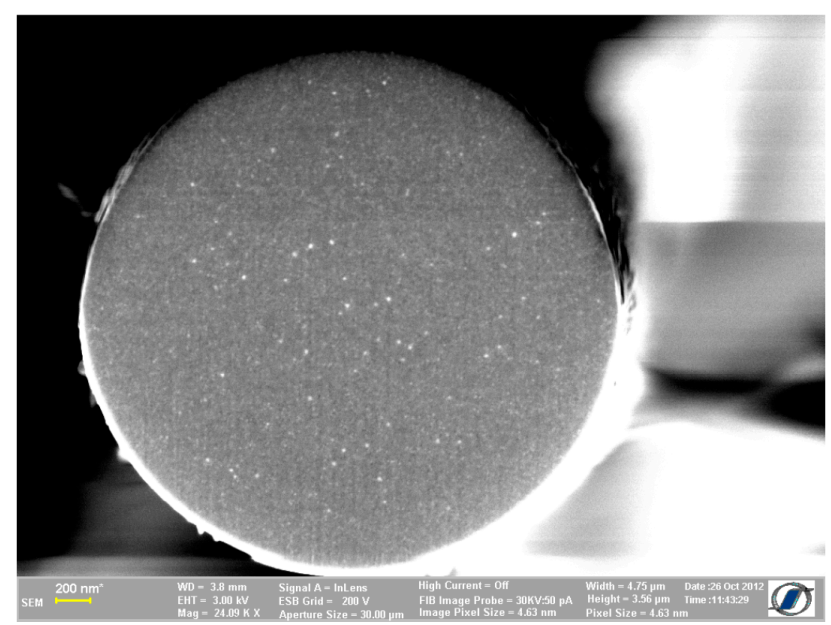

Figure 7. SEM micrograph of a glass-coated $\mathrm{Fe}_{73.5} \mathrm{Cu}_{1} \mathrm{Nb}_{3} \mathrm{Si}_{13.5} \mathrm{~B}_{9}$ thin microwire sample after annealing for $60 \mathrm{~min}$ at $550{ }^{\circ} \mathrm{C}$.

It clearly shows a microstructure specific to nanocrystalline materials, with 10-20 nm grains homogeneously dispersed within the residual amorphous matrix. The nanograins occupy about $50 \%$ from the visible cross section area. Annealing at $600{ }^{\circ} \mathrm{C}$ for $60 \mathrm{~min}$ leads to an increase of this fraction to nearly $65 \%$, showing that, indeed, annealing at $600{ }^{\circ} \mathrm{C}$ is more effective than at $550{ }^{\circ} \mathrm{C}$ in the case of thin samples. The ratio between the nanograins and the residual amorphous matrix was calculated using an image processing software.

Annealing at $650{ }^{\circ} \mathrm{C}$ for $60 \mathrm{~min}$ results in the increase of the crystalline grains up to 80-90 nm, along with the precipitation of the $\mathrm{Fe}_{2} \mathrm{~B}$ phase, as illustrated in Figure 8 . These two phases- $\alpha-\mathrm{FeSi}$ and $\mathrm{Fe}_{2} \mathrm{~B}$ - occupy over $75 \%$ of the sample volume.

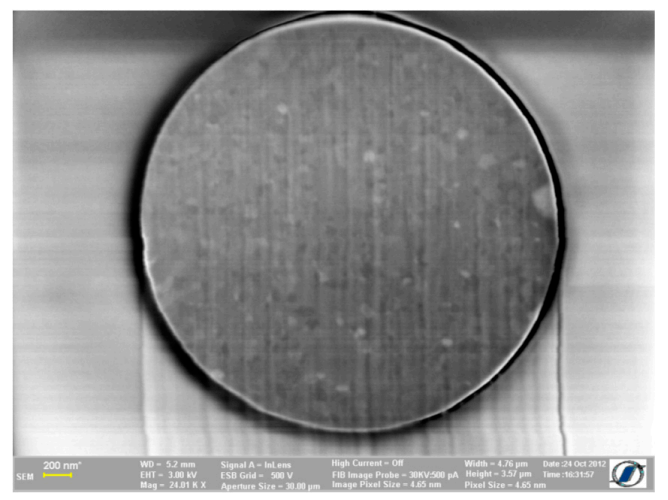

(a)

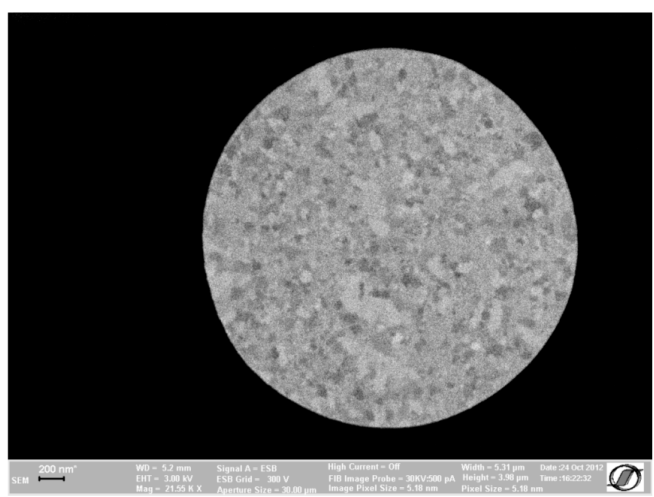

(b)

Figure 8. HR-SEM micrographs of a glass-coated $\mathrm{Fe}_{73.5} \mathrm{Cu}_{1} \mathrm{Nb}_{3} \mathrm{Si}_{13.5} \mathrm{~B}_{9}$ thin microwire sample after annealing for $60 \mathrm{~min}$ at $650{ }^{\circ} \mathrm{C}$ : (a) In-Lens detector image; and (b) BSE detector image. 
Figure 9 comparatively summarizes the dependence of the switching field on the annealing temperature, $H^{*}$ vs. $T_{a n n}$, for three ultrathin samples- $\Phi_{m}=185 \mathrm{~nm}, 320 \mathrm{~nm}$, and $450 \mathrm{~nm}$, respectively-with $t_{g}=5 \mu \mathrm{m}$ in all three cases, along with the microwire sample having $\Phi_{m}=3.5 \mu \mathrm{m}$ and $t_{g}=10 \mu \mathrm{m}$, employed as a reference. The annealing time was $60 \mathrm{~min}$.

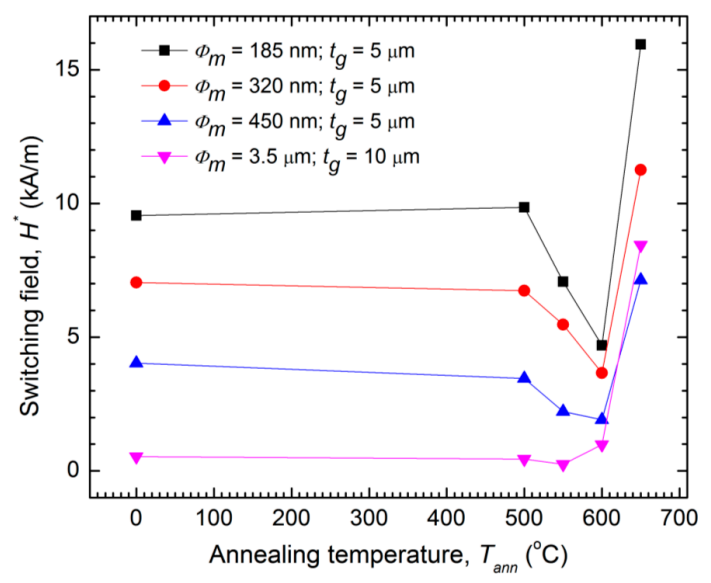

Figure 9. Dependence of the switching field on the annealing temperature for three ultrathin samples $\left(\Phi_{m}<1 \mu \mathrm{m}\right)$ and one microwire sample $\left(\Phi_{m} \geq 1 \mu \mathrm{m}\right)$.

One observes that for all the submicron wire samples, the most effective annealing, at which the minimum value is reached for $H^{*}$, is at $600{ }^{\circ} \mathrm{C}$, whilst in the case of the thicker microwire, the most effective annealing occurred at $550{ }^{\circ} \mathrm{C}$, for the same $t_{a n n}=60 \mathrm{~min}$. Why is this $50{ }^{\circ} \mathrm{C}$ difference? What is its origin? The answer should result from the unique combination of phases within the nanocrystalline structure $-\alpha$-FeSi nanosized grains and the residual, Fe-B rich, amorphous matrix —and the extremely fine balance between them.

The grains are homogeneously and randomly dispersed within the amorphous matrix. Depending on their size and density, they can be at various distances among them. The average inter-grain distance, $d$, should always be correlated with the exchange length, $L_{e x}$, of the $\alpha$-FeSi phase. When $d \leq L_{e x}$, the $\alpha$-FeSi grains are exchange coupled, and they exhibit a collective magnetic behavior, acting as a single phase from the point of view of their magnetic properties. On the contrary, when $d>L_{e x}$, there is no joint magnetic response of the nanosized grains, since they act isolated from each other from the point of view of the exchange interaction - their only interaction being of dipolar nature, which is much weaker, and takes place through the amorphous matrix, which makes it even more weak. The exchange length is inversely proportional to the magnetoelastic anisotropy constant of the wires $\left(L_{e x}=\sqrt{A / K_{m e}}\right)$, in which $A$ is the exchange parameter. Hence, the dimensions of the wires play a decisive role in determining the value of the exchange length. One such example is given in Reference [36], where $L_{e x}$ can vary from 27 to $39 \mathrm{~nm}$ in case of a nanocrystalline microwire with $30 \mu \mathrm{m}$ in diameter, following the removal of a $15 \mu \mathrm{m}$ thick glass coating. In the case of the thinner submicron wires and nanowires, internal stresses are much larger than in microwires, due to the much smaller radial dimensions involved in the rapid solidification process, and, therefore, $L_{e x}$ is expected to be quite smaller.

With this mechanism in mind, one can clearly understand why a larger annealing temperature is required to achieve the optimum inter-grain distance in the ultrathin wires. A slightly increased annealing temperature has two effects: (1) it triggers the nucleation of a larger number of grains, so that their density increases; and (2) it drives the grains to slowly grow. Both effects determine the nanosized grains to be closer to each other, so that they become exchange coupled even when $L_{e x}$ is smaller, as expected in the rapidly solidified nanowires and submicron wires. When this happens, the magnetostriction is averaged out, reaches minimum, although it is not necessarily as small as in the case of the thicker microwires, as proven by the major difference in the values of the switching field. 
Another effective way of studying the evolution of the correlation between structure and magnetic properties in the case of nanocrystalline materials is the investigation of the domain wall movement, since domain walls are expected to propagate faster in nanocrystalline magnetic materials, due to their low magnetic anisotropy. In the nanocrystalline glass-coated microwires, a good correlation has been observed between the optimum annealing procedure $\left(550^{\circ} \mathrm{C}\right.$ for $\left.60 \mathrm{~min}\right)$ and the domain wall velocity, in the sense that largest velocity values have been measured in the fully nanocrystallized samples [37].

Figure 10 shows the field dependence of the domain wall velocity in the case of a submicron $\mathrm{Fe}_{73.5} \mathrm{Cu}_{1} \mathrm{Nb}_{3} \mathrm{Si}_{13.5} \mathrm{~B}_{9}$ wire sample with $\Phi_{m}=320 \mathrm{~nm}$ and $t_{g}=5 \mu \mathrm{m}$ in the as-cast amorphous state, as well as after annealing for $60 \mathrm{~min}$ at $550{ }^{\circ} \mathrm{C}$ and $600{ }^{\circ} \mathrm{C}$, respectively.

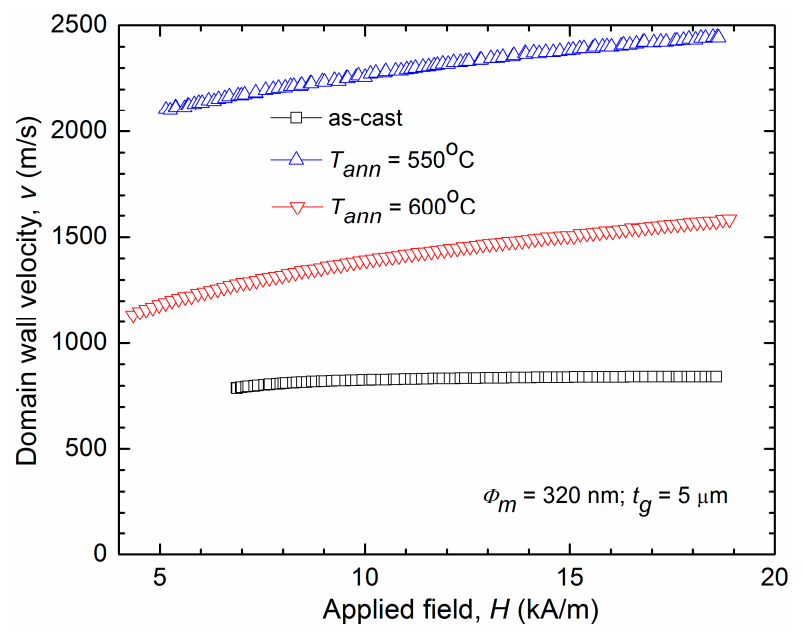

Figure 10. Dependence of the domain wall velocity on the applied magnetic field for a submicron $\mathrm{Fe}_{73.5} \mathrm{Cu}_{1} \mathrm{Nb}_{3} \mathrm{Si}_{13.5} \mathrm{~B}_{9}$ sample with $\Phi_{m}=320 \mathrm{~nm}$ in as-cast state and after annealing for $60 \mathrm{~min}$ at $550{ }^{\circ} \mathrm{C}$ and $600{ }^{\circ} \mathrm{C}$, respectively.

One can see that the as-cast sample displays the slowest domain walls, with the average velocity around $800 \mathrm{~m} / \mathrm{s}$. Annealing at $550{ }^{\circ} \mathrm{C}$ leads to a significant increase in the domain wall velocity, which reaches to values well above $2000 \mathrm{~m} / \mathrm{s}$. Annealing at $600^{\circ} \mathrm{C}$ on the other hand, leads to higher velocities than those encountered in the as-cast amorphous sample, nevertheless, at values between 1100 and $1500 \mathrm{~m} / \mathrm{s}$, they are noticeably smaller than those measured in the sample annealed at $550{ }^{\circ} \mathrm{C}$.

Accordingly, in the case of the ultrathin $\mathrm{Fe}_{73.5} \mathrm{Cu}_{1} \mathrm{Nb}_{3} \mathrm{Si}_{13.5} \mathrm{~B}_{9}$ wires, the largest values of the domain wall velocity do not correspond to the most effective annealing, i.e., the one that results in the lowest values of the switching field, namely $600{ }^{\circ} \mathrm{C}$.

Considering the above explanations regarding the correlation between $d$ and $L_{e x}$, we can state that, in case of the ultrathin wire annealed at $550{ }^{\circ} \mathrm{C}$, the coupling between the $\alpha$-FeSi grains is not yet achieved as $d$ is still larger than $L_{e x}\left(d>L_{e x}\right)$. This happens due to the smaller characteristic exchange length, $L_{e x}$, of the ultrathin wires (nanowires and submicron wires), as pointed out previously. Therefore, the sample's magnetic characteristics, including those of the magnetic domain wall propagation, are still determined by the amorphous phase, as the nanosized grains do not count yet as a single, well-determined, phase. This is an advantage, as one observes from the domain wall velocity data illustrated in Figure 10, since the amorphous wires and microwires generally display large values of the domain wall velocity and mobility [38]. In this case, we have a 'nearly-nanocrystalline' state, or a "close-to-nanocrystalline" state, in which the nanograins exist, but are decoupled, allowing the amorphous matrix to still impose its characteristics globally, onto the entire nanowire. This explanation is supported by the UHR-TEM, STEM and SAED images shown in Figure 11c,d. More importantly, the amorphous phase is stress relieved due to annealing, being much softer from the magnetic point of view than an as-cast amorphous phase. This may result in significantly higher domain wall propagation velocities. 


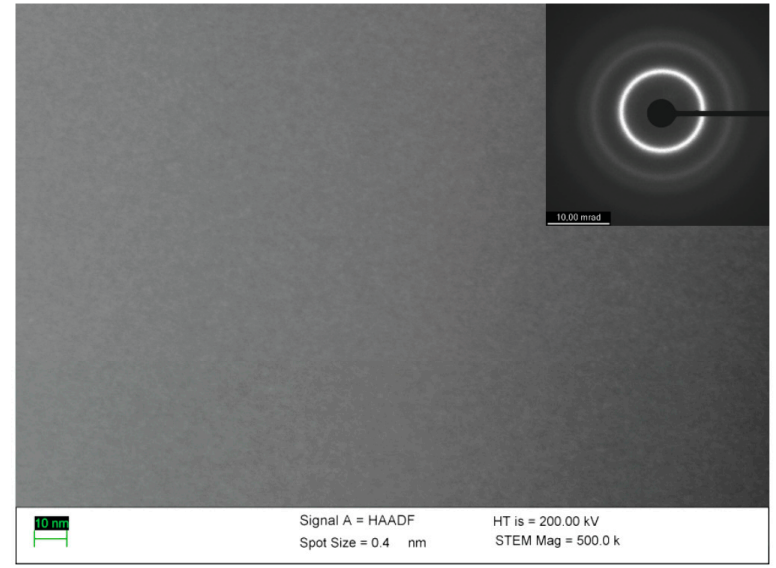

(a)

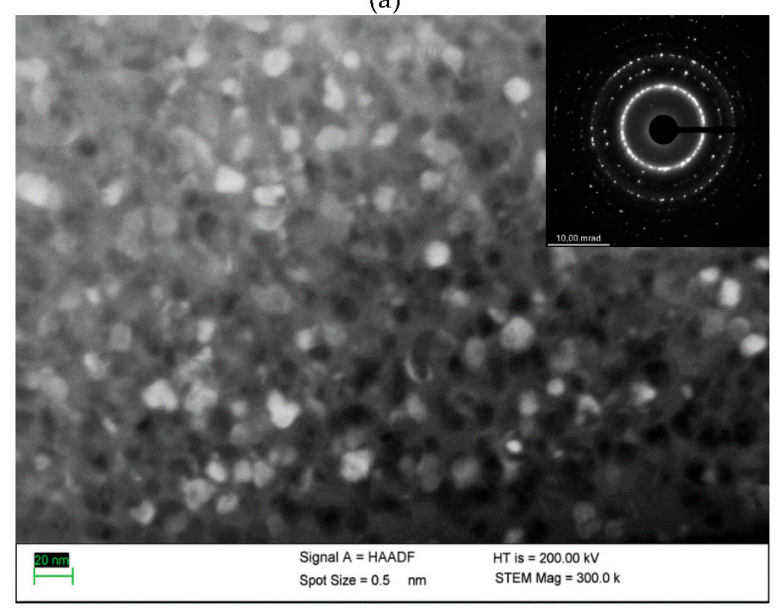

(c)

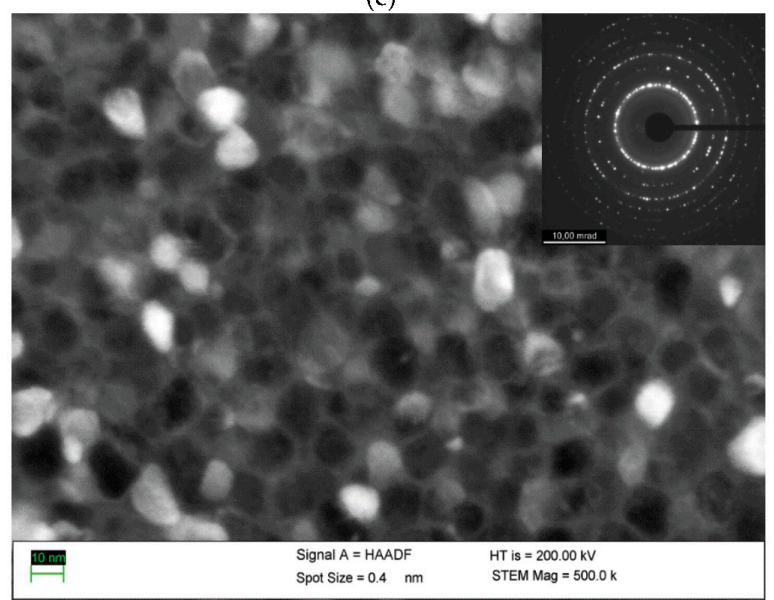

(e)

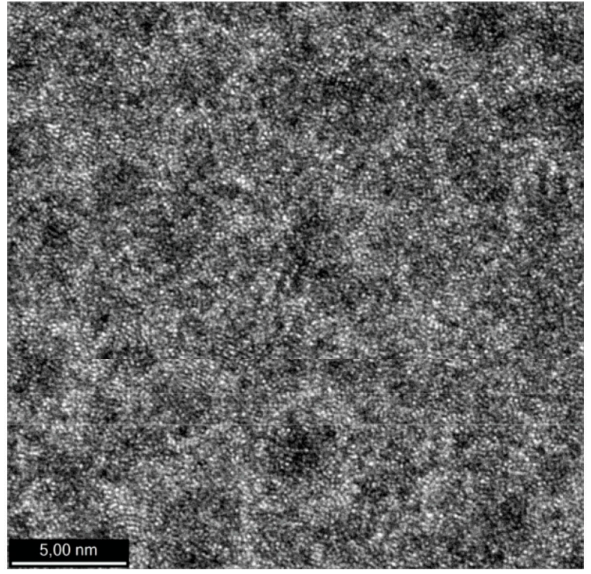

(b)

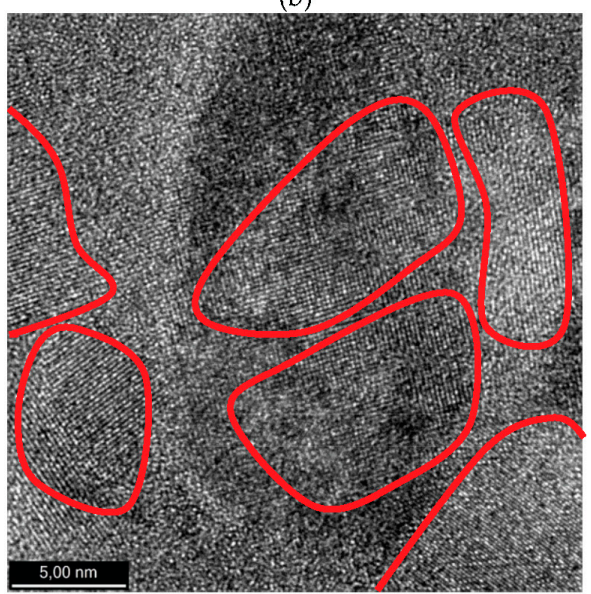

(d)

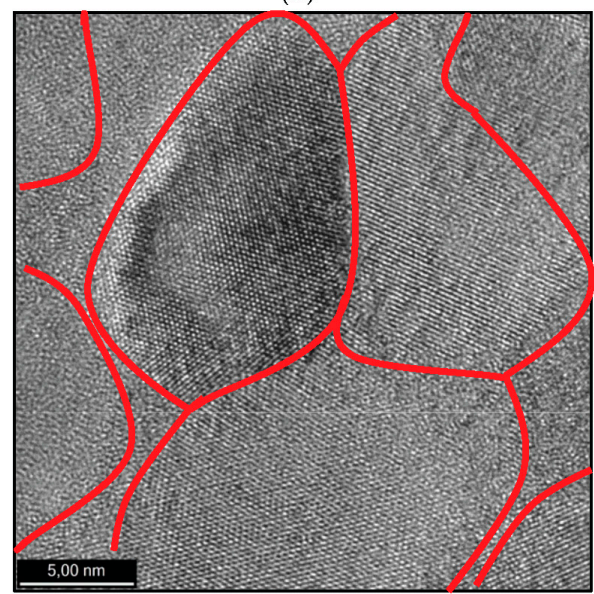

(f)

Figure 11. Evolution of the microstructure of a FINEMET nanowire having the metallic nucleus diameter of $320 \mathrm{~nm}$ : (a) STEM and SAED images and (b) UHR-TEM image for the as-cast amorphous sample; (c) STEM and SAED images and (d) UHR-TEM image for the sample annealed at $550{ }^{\circ} \mathrm{C}$ for 60 min.; (e) STEM and SAED images and (f) UHR-TEM image for the sample annealed at $600{ }^{\circ} \mathrm{C}$ for $60 \mathrm{~min}$.

A slightly more elevated annealing temperature, i.e., $600^{\circ} \mathrm{C}$, results in the achievement of the condition $d \leq L_{e x}$, and implicitly of the nanocrystalline structure, with the coupled $\alpha$-FeSi grains, as illustrated in Figure 11e,f. Nevertheless, the nanocrystalline structure in this case is expected to be 
slightly different as compared to that encountered in microwires and 'conventional' wires, with more closely packed grains. Therefore, the velocity, although high enough, is smaller than after annealing at $550^{\circ} \mathrm{C}$.

Summarizing, the interplay between the value of the specific exchange length expected in the ultrathin FINEMET type glass-coated wires (nanowires and submicron wires) and the inter-grain distance after various stages of annealing, are capable of explaining the observed peculiarities in the magnetic behavior of these novel, wire-shaped materials. Generally, the average grain size for nanowire samples annealed at $550{ }^{\circ} \mathrm{C}$ and $600{ }^{\circ} \mathrm{C}$ is below $10 \mathrm{~nm}(7$ and $9 \mathrm{~nm}$, respectively, calculated from the Gauss distribution of grain sizes), less than in the case of microwires and ribbons, which can reach up to $20 \mathrm{~nm}$.

The appropriate dimensions of their actual magnetic part-the metallic nucleus-along with the enhanced values of the domain wall velocities indeed recommend them as potential candidates in domain wall conduits for future magnetic domain wall logic based devices [39]. Besides this potential future application, other applications may be also envisaged, especially considering the ease of their manipulation, due to the existence of the rather thick non-magnetic glass coating. One such application would be as miniature sensing elements in micro and nanosensors aimed for implantable or non-implantable medical devices, e.g., stress or deformation microsensors [40]. Another area of interest would be in the field of high frequency applications, due to their extremely small transverse dimensions, where they could be employed to create radio wave absorbing structures for electromagnetic shielding applications [41] or for other applications that require the tuning of the electromagnetic response of left-handed ferromagnetic wires [42] or of left-handed wires in which ferromagnetic antiresonance (FMAR) has been emphasized [43]. High frequency applications of ordered arrays of such nanowires are also of great interest [44].

\section{Conclusions}

The correlation between the magnetic behavior of submicron and nanometric $\mathrm{Fe}_{73.5} \mathrm{Cu}_{1} \mathrm{Nb}_{3} \mathrm{Si}_{13.5} \mathrm{~B}_{9}$ wires and their structural evolution following different stages of annealing shows that these very thin samples require slightly more elevated annealing temperatures than the thicker "conventional" wires or glass-coated microwires with similar composition in order to become nanocrystalline. This is due to their much smaller diameters, larger frozen-in stresses during preparation, and corresponding smaller exchange length, which requires larger temperature to reduce the inter-grain distance.

On the other hand, this particular feature allows large domain wall velocity values in these bistable ultrathin wires, mostly due to the preservation of the role played by the residual amorphous matrix in their magnetic behavior, even after significant annealing, which also relieves the large stresses induced during preparation, resulting in the further reduction in the magnetoelastic anisotropy within the matrix.

Essentially, all the observed characteristics of the $\mathrm{Fe}_{73.5} \mathrm{Cu}_{1} \mathrm{Nb}_{3} \mathrm{Si}_{13.5} \mathrm{~B}_{9}$ magnetic nanocrystalline submicron wires and nanowires can be phenomenologically interpreted by taking into account the correlation between the expected small exchange length and the changes in the inter-grain distance with annealing.

Acknowledgments: This work was supported by the Romanian Ministry of Research and Innovation through the NUCLEU Program PN 16370202 and by the Executive Agency for Higher Education, Research, Development and Innovation Funding (UEFISCDI) under Contract No. 46/2013 (Project PN-II-ID-PCE-2012-4-0424).

Author Contributions: Horia Chiriac, Nicoleta Lupu and Sorin Corodeanu conceived and designed the experiments; George Stoian performed the scanning electron microscopy measurements and prepared the thin TEM lamellas by focused ion beam, Gabriel Ababei performed the transmission electron microscopy measurements, and Sorin Corodeanu the annealing, hysteresis loops and domain wall velocity measurements; Horia Chiriac and Nicoleta Lupu analyzed the data; Tibor-Adrian Óvári provided the phenomenological explanation based on the correlation between the annealing-induced changes in the inter-grain distance and the specific exchange length and wrote the paper.

Conflicts of Interest: The authors declare no conflict of interest. 


\section{References}

1. Gemperle, R.; Kraus, L.; Schneider, J. Magnetization reversal in amorphous $\left(\mathrm{Fe}_{1-\mathrm{x}} \mathrm{Ni}_{\mathrm{x}}\right)_{80} \mathrm{P}_{10} \mathrm{~B}_{10}$ microwires. Czechoslov. J. Phys. 1978, 28, 1138-1145. [CrossRef]

2. Humphrey, F.B.; Mohri, K.; Yamasaki, J.; Kawamura, H.; Malmhäll, R.; Ogasawara, I. Re-entrant magnetic flux reversal in amorphous wires. In Magnetic Properties of Amorphous Metals; Hernando, A., Madurga, V., Sánchez-Trujillo, M.C., Vázquez, M., Eds.; North-Holland Publishing Company: Amsterdam, The Netherlands, 1987; pp. 110-116.

3. Morón, C.; Cabrera, C.; Morón, A.; García, A.; González, M. Magnetic sensors based on amorphous ferromagnetic materials: A review. Sensors 2015, 15, 28340-28366. [CrossRef]

4. Nakayama, S.; Uchiyama, T. Real-time measurement of biomagnetic vector fields in functional syncytium using amorphous metal. Sci. Rep. 2015, 5, 8837. [CrossRef] [PubMed]

5. Zhukov, A.; Ipatov, M.; Churyukanova, M.; Kaloshkin, S.; Zhukova, V. Giant magnetoimpedance in thin amorphous wires: From manipulation of magnetic field dependence to industrial applications. J. Alloys Compd. 2014, 586, S279-S286. [CrossRef]

6. Vázquez, M. Soft magnetic wires. Phys. B Condens. Matter 2001, 299, 302-313. [CrossRef]

7. Bordin, G.; Buttino, G.; Cecchetti, A.; Poppi, M. Peculiar behavior of the magneto-impedance in Fe-based amorphous wires under torsion. J. Magn. Magn. Mater. 2000, 222, 257-262. [CrossRef]

8. Sinnecker, J.P.; Tiberto, P.; Kurlyandskaia, G.V.; Sinnecker, E.H.C.P.; Vázquez, M.; Hernando, A. Hysteretic giant magneto impedance. J. Appl. Phys. 1998, 84, 5814-5816. [CrossRef]

9. Sánchez, M.L.; Hernando, B.; Olivera, J.; Prida, V.M.; Santos, J.D.; Pérez, M.J.; Gorría, P. Torsion and magnetic field effect in the impedance of FeSiBNbCu soft magnetic amorphous wires. J. Magn. Magn. Mater. 2006, 304, e865-e867. [CrossRef]

10. Baranov, S.A.; Zotov, S.K.; Larin, V.S.; Torkunov, A.V. Structure and properties of an amorphous microwire. Met. Sci. Heat Treat. 1992, 34, 581-583. [CrossRef]

11. Vázquez, M.; García, K.L. Influence of the magnetoelastic mechanism on the switching field fluctuations of Fe-based amorphous microwires. Czechoslov. J. Phys. 2004, 54, D17-D22. [CrossRef]

12. Zhukov, A.; Talaat, A.; Churyukanova, M.; Kaloshkin, S.; Semenkova, V.; Ipatov, M.; Blanco, J.M.; Zhukova, V. Engineering of magnetic properties and GMI effect in Co-rich amorphous microwires. J. Alloys Compd. 2016, 664, 235-241. [CrossRef]

13. Ogasawara, I.; Ueno, S. Preparation and properties of amorphous wires. IEEE Trans. Magn. 1995, 31, 1219-1223. [CrossRef]

14. Zhao, Y.Y.; Li, H.; Hao, H.Y.; Li, M.; Zhang, Y.; Liaw, P.K. Microwires fabricated by glass-coated melt spinning. Rev. Sci. Instrum. 2013, 84, 075102. [CrossRef] [PubMed]

15. Beach, R.S.; Berkowitz, A.E. Giant magnetic field dependent impedance of amorphous FeCoSiB wire. Appl. Phys. Lett. 1994, 64, 3652-3654. [CrossRef]

16. Panina, L.V.; Mohri, K. Magneto-impedance effect in amorphous wires. Appl. Phys. Lett. 1994, 65, $1189-1191$. [CrossRef]

17. Hauser, H.; Kraus, L.; Ripka, P. Giant magnetoimpedance sensors. IEEE Instrum. Meas. Mag. 2001, 4, $28-32$. [CrossRef]

18. Beach, R.S.; Smith, N.; Platt, C.L.; Jeffers, F.; Berkowitz, A.E. Magneto-impedance effect in NiFe plated wire. Appl. Phys. Lett. 1996, 68, 2753-2755. [CrossRef]

19. Sirisathitkul, C.; Jantaratana, P. Magnetoimpedance of electroplated wires with large core diameters. J. Mater. Sci. Technol. 2009, 25, 825-828.

20. Kurlyandskaya, G.V.; García-Miquel, H.; Vázquez, M.; Svalov, A.V.; Vas'kovskiy, V.O. Longitudinal magnetic bistability of electroplated wires. J. Magn. Magn. Mater. 2002, 249, 34-38. [CrossRef]

21. Marín, P.; Vázquez, M.; Arcas, J.; Hernando, A. Thermal dependence of magnetic properties in nanocrystalline FeSiBCuNb wires and microwires. J. Magn. Magn. Mater. 1999, 203, 6-11. [CrossRef]

22. Yoshizawa, Y.; Oguma, S.; Yamauchi, K. New Fe-based soft magnetic alloys composed of ultrafine grain structure. J. Appl. Phys. 1988, 64, 6044-6046. [CrossRef]

23. Herzer, G. Nanocrystalline soft magnetic materials. J. Magn. Magn. Mater. 1992, 112, 258-262. [CrossRef]

24. Allia, P.; Baricco, M.; Tiberto, P.; Vinai, F. Kinetics of the amorphous to nanocrystalline transformation in $\mathrm{Fe}_{73.5} \mathrm{Cu}_{1} \mathrm{Nb}_{3} \mathrm{Si}_{13.5} \mathrm{~B}_{9}$. J. Appl. Phys. 1993, 74, 3137-3143. [CrossRef] 
25. Chiriac, H.; Óvári, T.-A.; Pop, G.H.; Barariu, F. Magnetic behavior of nanostructured glass covered metallic wires. J. Appl. Phys. 1997, 81, 5817-5819. [CrossRef]

26. Chiriac, H.; Corodeanu, S.; Donac, A.; Dobrea, V.; Ababei, G.; Stoian, G.; Lostun, M.; Óvári, T.-A.; Lupu, N. Influence of cold drawing on the magnetic properties and giant magneto-impedance response of FINEMET nanocrystalline wires. J. Appl. Phys. 2015, 117, A314. [CrossRef]

27. Iskhakov, R.S.; Komogortsev, S.V. Magnetic microstructure of amorphous, nanocrystalline, and nanophase ferromagnets. Phys. Met. Metallogr. 2011, 112, 666-681. [CrossRef]

28. Prida, V.M.; Gorría, P.; Kurlyandskaya, G.V.; Sánchez, M.L.; Hernando, B.; Tejedor, M. Magneto-impedance effect in nanostructured soft ferromagnetic alloys. Nanotechnology 2003, 14, 231-238. [CrossRef]

29. Chiriac, H.; Corodeanu, S.; Lostun, M.; Stoian, G.; Ababei, G.; Óvári, T.-A. Rapidly solidified amorphous nanowires. J. Appl. Phys. 2011, 109, 063902. [CrossRef]

30. Chizhik, A.; Zhukov, A.; Gonzalez, J.; Stupakiewicz, A. Control of the domain wall motion in cylindrical magnetic wires. Appl. Phys. Lett. 2016, 109, 052405. [CrossRef]

31. Óvári, T.-A.; Lupu, N.; Chiriac, H. Magnetic nanowires and submicron wires prepared by the quenching and drawing technique. In Magnetic Nano- and Microwires; Vázquez, M., Ed.; Woodhead Publishing: Cambridge, UK, 2015; pp. 199-223.

32. Mayer, J.; Giannuzzi, L.A.; Kamino, T.; Michael, J. TEM sample preparation and FIB-induced damage. MRS Bull. 2007, 32, 400-407. [CrossRef]

33. Corodeanu, S.; Chiriac, H.; Lupu, N.; Óvári, T.-A. Magnetic characterization of submicron wires and nanowires using digital integration techniques. IEEE Trans. Magn. 2011, 47, 3513-3515. [CrossRef]

34. Butta, M.; Infante, G.; Ripka, P.; Badini-Confalonieri, G.A.; Vázquez, M. M-H loop tracer based on digital signal processing for low frequency characterization of extremely thin magnetic wires. Rev. Sci. Instrum. 2009, 80, 083906. [CrossRef] [PubMed]

35. Corodeanu, S.; Chiriac, H.; Óvári, T.-A. Accurate measurement of domain wall velocity in amorphous microwires, submicron wires, and nanowires. Rev. Sci. Instrum. 2011, 82, 094701. [CrossRef] [PubMed]

36. Corodeanu, S.; Óvári, T.-A.; Lupu, N.; Chiriac, H. Magnetization process and GMI effect in as-cast nanocrystalline microwires. IEEE Trans. Magn. 2010, 46, 380-382. [CrossRef]

37. Chiriac, H.; Tibu, M.; Óvári, T.-A. Domain wall propagation in nanocrystalline glass-coated microwires. IEEE Trans. Magn. 2009, 45, 4286-4289. [CrossRef]

38. Varga, R.; Zhukov, A.; Blanco, J.M.; Ipatov, M.; Zhukova, V.; Gonzalez, J.; Vojtanik, P. Fast magnetic domain wall in magnetic microwires. Phys. Rev. B 2006, 74, 212405. [CrossRef]

39. Cowburn, R.P. Magnetic nanowires for domain wall logic and ultrahigh density data storage. In Nanoscale Magnetic Materials and Applications; Liu, J.P., Fullerton, E., Gutfleisch, O., Sellmyer, D.J., Eds.; Springer: New York, NY, USA, 2009; pp. 219-236.

40. Tan, E.L.; Pereles, B.D.; Horton, B.; Shao, R.; Zourob, M.; Ong, K.G. Implantable biosensors for real-time strain and pressure monitoring. Sensors 2008, 8, 6396-6406. [CrossRef] [PubMed]

41. Berzhansky, V.N.; Ponomarenko, V.I.; Popov, V.V.; Torkunov, A.V. Measuring the impedance of magnetic microwires in a rectangular waveguide. Tech. Phys. Lett. 2005, 31, 959-960. [CrossRef]

42. García-Miquel, H.; Carbonell, J.; Sánchez-Dehesa, J. Modulation of electromagnetic waves by alternating currents through left-handed ferromagnetic microwires. J. Appl. Phys. 2012, 111, 063901. [CrossRef]

43. García-Miquel, H.; Carbonell, J.; Sánchez-Dehesa, J. Left handed material based on amorphous ferromagnetic microwires tunable by dc current. Appl. Phys. Lett. 2010, 97, 094102. [CrossRef]

44. Makeeva, G.S.; Golovanov, O.A. The electromagnetic analysis of propagation constants of electromagnetic waves in 3D magnetic nanowire lattices under the magnetic resonance conditions at microwaves. J. Commun. Technol. Electron. 2016, 61, 1-9. [CrossRef]

(C) 2017 by the authors; licensee MDPI, Basel, Switzerland. This article is an open access article distributed under the terms and conditions of the Creative Commons Attribution (CC BY) license (http:/ / creativecommons.org/licenses/by/4.0/). 